\title{
Bullous pemphigoid
}

INSERM

\section{Source}

INSERM. (1999). Orphanet: an online rare disease and orphan drug data base. Bullous pemphigoid. ORPHA:703

Bullous pemphigoid (BP) is the most common form of autoimmune bullous dermatosis. 